\title{
The Importance of Trailblazing Scholarship for Understanding Entrepreneurship
}

"Do not go where the path may lead; go instead where there is no path and leave a trail."

-Ralph Waldo Emerson

Recently, the co-authors of this book met in Blairgowrie, Australia. Dean Shepherd showed Holger Patzelt the Back Beach where he had spent much of his youth. Dean recalled his childhood taking the trek from his house along the path through the coastal reserve to the rock pool and surf:

Although the path made the trip relatively quick, easy, and safe, it was a somewhat boring walk. Sometimes my brother and I took a narrower path to see a less populated section of the beach, and other times, we created our own path-a route that no one else had taken. We called it "bushwhacking" because we had to beat our way through the dense tea-tree. We did this to explore. This new path was always slower than the normal route as well as less comfortable (with branches scratching and long grasses poking) and less safe (with the chance of coming across poisonous snakes and/or spiders), but we did it anyway. We held out hope this new path would lead to a new sand dune we could tumble down, a new vista we could appreciate, a cave to hide in, or a rock pool within which we could dive and swim. But even when we did not find one of these desirable outcomes and spent hours walking only to find that we had returned to our original starting point, we had enjoyed every minute of it. 
This description of bushwhacking is the Australian version of trailblazing, and metaphorically, entrepreneurs can also be trailblazers-make a path through new or unsettled terrain upon which others may follow. That is, rather than follow the established path created by others, entrepreneurs often challenge the status quo by attempting to chart a new direction through the creation of new products, services, and/ or processes. However, this book is not about trailblazing in coastal reserves or in product markets but about trailblazing in the field of entrepreneurship. We believe that scholars can be trailblazers, and in doing so, they can create new knowledge that others can build on to create additional knowledge and inform practice. Although this trailblazing may not have to deal with the poisonous snakes and spiders of Australia, it certainly has its fair share of obstacles, requires considerable effort, and may also lead to dead ends. Along with the challenges of creating a new trail are the intrinsic rewards from the process and the extrinsic rewards from the outcomes of making substantial contributions to knowledge. For scholars traveling along a well-worn path or a semi-worn path, the research outcomes are replication and incremental research, whereas trailblazing creates new knowledge through more radical ideas. Important in trailblazing is knowing where to start and having some knowledge about the terrain to be covered, the tools to help clear the path, and the potential "gems" that might be encountered along the way. The purpose of this book is to provide some insights into where trailblazing may be best directed, how, and with what potential outcomes. Specifically, this book offers a series of frameworks from which or within which we believe important research will emerge-research that will have a substantial impact on our understanding of an entrepreneurial phenomenon and, thus, on the way we progress with subsequent entrepreneurship research.

We emphasize trailblazing (as opposed to taking existing paths) because we strongly believe that the future of the entrepreneurship field is promising but only if our research itself continues to be entrepreneurial. That being said, continuing to be entrepreneurial in our research may be more difficult than it initially appears. The success we have had thus far may lead us into a competency trap (Levitt \& March, 1988) that rewards us in the short term but is detrimental to the field in the long term. That is, entrepreneurship researchers sometimes decide to "play it safe," using "accepted" theories and methods to answer progressively narrower research questions 
that are of interest to smaller and smaller audiences (i.e., taking the known path). By no means are we arguing that this type of incremental research does not make important contributions to the field. Rather, we are suggesting that if incremental research starts to dominate and overtake more trailblazing research, the field could begin to stagnate and lose the essence that makes it special-namely, the very real and pervasive willingness to accept substantial novelty in the way we question, theorize, and test ideas to develop new and stimulating insights. ${ }^{1}$

As we consider the entrepreneurship field's future, our goal with this book is not to decry or replace Venkataraman's (Shane \& Venkataraman, 2000; Venkataraman, 1997) or others' (e.g., Busenitz et al., 2003; Carlsson et al., 2013; Davidsson, 2003; Gartner, 1990; Wiklund, Davidsson, Audretsch, \& Karlsson, 2011) description of entrepreneurship's characteristic domain with our own; rather, our goal is to illuminate areas of unsettled terrain worthy of trailblazing work as a basis for the vitality of the field's future. Such trailblazing is likely to continuously alter what is considered to be entrepreneurship. As researchers, we should maybe focus less on whether our current work conforms to published domain statements within the entrepreneurship field because the field itself has likely already shifted. Our current work may make a more substantial contribution to the field by expanding its boundaries further by, for instance, opening up new terrain that then becomes part of the field of entrepreneurship (in retrospect).

Indeed, researchers from a variety of fields tend to focus narrowly on prevailing principles and themes, which can homogenize knowledge creation (in the literature) about the diverse world (Glynn, Barr, \& Dacin, 2000). More specifically, Kuhn (2012) classified fields of study based on the extent to which they create paradigms-namely, "shared theoretical structures and methodological approaches about which there is a high level of consensus" (Cole, 1983, p. 112). When a paradigm is more developed, there is less uncertainty about knowledge production as well as less fragmentation, both of which appear to lead to growth in a field (Pfeffer, 1993). That is, agreement about core assumptions - namely, of the nature of "knowledge [ontology], the nature of knowledge about those phenomena [epistemology], and the nature of ways of studying those phenomena [methodology]" Gioia \& Pitre, 1990, p. 585) — can result in more knowledge accumulation (Pfeffer, 1993). Stemming from these ideas, Davidsson (2003) bemoaned that entrepreneurship research occasionally 
suffers from an abundance of studies articulated on different core principles and assumptions-a practice that has resulted in slow knowledge accumulation in the field. These arguments are consistent with those for the benefits of well-established paths.

While there is a great deal of value in knowledge-accumulation arguments, this paradigm-development approach seems to prefer parsimony and consistency above depth and diversity. As a result, this approach has the potential to generate an exceedingly narrow view (Burrell \& Morgan, 1979), particularly considering the rich nature of entrepreneurial phenomena. Indeed, as researchers, we need to keep up with the intricacies of the phenomena we explore, which we can begin doing by taking an array of perspectives to develop an assortment of interpretations (Glynn et al., 2000). Namely, the "paradigm mentality simultaneously proliferates and polarizes perspectives, often inhibiting discourse across paradigms, biasing theorists against opposing explanations and fostering development of provincial theories" (Lewis \& Grimes, 1999, p. 672)-all with the aim of winning the "paradigm war." In this context, the more exploratory is overtaken by the more exploitive. Indeed, this mindset is like putting up wire fences to dissuade people from leaving the path to create their own.

\section{ENTREPRENEURSHIP AND BEYOND}

Although our primary intent with this book is to advance the field of entrepreneurship (without specifying the domain of entrepreneurship), we are conscious that in doing so, we have an opportunity to make contributions to knowledge that also advance other fields. Indeed, in many instances throughout the book, we focus our attention at the boundaries of current entrepreneurship theories, particularly constructs and relationships in the gray area between overlapping paradigms, levels of analysis, and fields of knowledge. This focus provides a systematic search, "the search of known information sources" (see Fiet, 2007, p. 595), for potential opportunities to advance our understanding of entrepreneurial phenomena-that is, to blaze a new trail. In particular, we start with topics we have some knowledge about and considerable interest in (i.e., familiar paths) to begin to search for and explore potential research opportunities (i.e., from which to trailblaze). Therefore, in justifying the basis for our search, we end up citing a number of our previous studies - not because we are so arrogant to believe that they represent the only basis upon which future contri- 
butions can be made to the field of entrepreneurship but because they represent "known information sources" (consistent with systematic search [Fiet, 2007]).

\section{Potential Research Opportunities and Research Methods}

The precursor to this book was the "Party On" paper (Shepherd, 2015), which challenged us, as scholars, to remain entrepreneurial and pursue areas of vitality (largely recounted in Chap. 2). We built on these notions to explore other areas that could be trailblazed to provide further vitality to the field. Although we discuss the content of research opportunities that we believe can advance our knowledge, we do not investigate the research methods necessary to empirically pursue these potential opportunities (with the possible exception of a brief discussion of conjoint analysis in Chap. 8). We are agnostic about research methods. Rather, we are pluralistic. We believe that the appropriateness of a particular research method depends on the research question and likely the knowledge and motivation of the researcher. It could be that multiple methods could be used to approach the same research opportunity, although it is likely that the operationalizations, sample context, and so forth may be so different such that they represent a different (but related) research opportunity; one that may be complementary in knowledge production. This is a good thing. Consistent results provide confidence in our knowledge based on replication. Differences in results signal the need for additional theorizing-a win-win.

Although the above assumes that the new content of our theorizing on an entrepreneurial phenomenon can be tested using (multiple) established research methods, we recognize that some research questions and/or conjectures may require the creation of new methods-new to entrepreneurship but established elsewhere, new combinations of multiple methods, or the creation of "new to the world" methods. However, the creative process does not necessarily need to be from content to method; it could be the other way around. As new methods are developed and introduced, we believe that they will open up new conceptual domains-new methods lead to new content. Therefore, although we focus on the importance of being entrepreneurial in our theorizing for advancing the field, we also recognize the importance of being entrepreneurial in our methods and welcome such advancements. 


\section{Assumptions and Boundary Conditions}

Just as we do not focus on a particular research method, we also do not focus on one particular philosophical perspective. We realize that people may be able to read into this book a philosophical perspective that we have applied subconsciously. However, we wish to point out that we believe that it is perfectly fine for people to approach their research from different philosophical perspectives. Indeed, it is better than fine because these different lenses can provide deeper insight into entrepreneurial phenomena and advance the field (even this statement is replete with unintended philosophical undertones). We like to think of different philosophical perspectives as enabling diverse knowledge creation, which is important for the vitality of the field. However, we realize that it can also constrain our thinking. To avoid constraining our thinking about research, we try to use the following rules of thumb in writing this book (and in writing and reviewing papers as well as making editorial decisions on papers) as the primary purpose is not to make a philosophical contribution:

1. We try to acknowledge the key assumptions and boundary conditions of our theorizing for the focal work.

2. We build on and direct our contributions of the focal work to the ongoing scholarly conversation that has similar assumptions and boundary conditions.

3. We allow others to use different philosophical perspectives in their papers and try to be aware of our potential biases (if any) in reading those papers.

4. We allow ourselves to use one philosophical perspective in one paper and a different philosophical perspective in a different paper (i.e., philosophically consistent within a paper but not necessarily across papers).

5. We do not acknowledge a "debate" about philosophical differences that may exist in the literature unless the specific purpose of the paper is to add something substantial to that debate.

6. We do not try to interpret a study as supporting one philosophical perspective over another nor suggest that one philosophical perspective is superior to another.

7. We do not re-interpret the findings of the study from a different philosophical perspective.

8. We realize that we are highly fallible in all of the above but dedicated to open mindedness. 
These are the rules that we try to follow. We find that they help us keep an open mind about research and avoid being pulled into endless discussions that seem to go nowhere other than around and around and around again. Like a merry-go-round, we realize that the circles, the ups and downs, the lights, and the bells and whistles of philosophical debates are enticing (like moths drawn to a flame), but because we are unwilling to spend a career trying to gain (and probably never fully achieving) an understanding of these deep and complicated issues, we avoid the temptation of "dabbling" (or at least we try). We also realize that contributions can be made by trained philosophers in exploring these issues.

\section{IMPLiCATIONS FOR ENTREPRENEURIAL SCHOLARS}

While trailblazing can sound exciting, as we mentioned above, it is more likely that incremental (i.e., exploitation) research has begun to crowd out trailblazing (i.e., exploration) research to the detriment of the field. This crowding out can be caused by individual scholars who want to take advantage of the legitimacy and popularity of the entrepreneurship field to focus on providing many incremental contributions, for instance, by adding another moderator to an extensive list of moderators of an existing main-effect relationship. This may seem to be a prudent research approach for a sole scholar, and it does contribute to the literature; however, if the majority of scholars use this strategy and are rewarded for doing so, we run into the "crowding-out effect" that we are worried about.

While it is understandable why some scholars, especially junior scholars, might take this approach, we put forth two cautionary observations and a challenge. First, the biggest risk when attempting to publish work in prestigious journals is using a conservative research strategy. Similar to the higher outcome variance in more entrepreneurial organizations (McGrath, 1999), entrepreneurial scholars are also likely to experience greater variance in research outcomes. Totally mixing metaphors, we argue that some trailblazing projects are likely to completely "bomb," whereas other projects could end up being "home runs" (i.e., they are able to capture editors', reviewers', and audiences' attention). Scholars who are organizing new research projects often use these "home run" entrepreneurial papers to develop their own stories. Thus, entrepreneurial scholars' published papers are likely to influence the development of the field (as well as other fields) more significantly than less entrepreneurial scholars' papers (even though entrepreneurial scholars are likely to experience higher project failure rates). 
Second, researchers can consider taking a portfolio approach with their projects, combining more radical research projects with "safer" projects. As entrepreneurial scholars, we can build a portfolio of projects that includes a few studies we believe are trailblazing (i.e., are odd, peculiar, and/or challenge the status quo). This approach is in line with the real options reasoning approach many organizations take to deal with the uncertainty underlying potential opportunities (McGrath, 1999).

Third, the challenge we present herein is to broaden the array of research questions, theories, and methods and to look to the "flipside" of prominent research streams for inspiration. For instance, entrepreneurship researchers trust there are benefits resulting from entrepreneurial action, so they generally focus on exploring those benefits. However, only studying benefits may lead to an incomplete picture. Different research questions and theories may be necessary to fully comprehend the costs associated with entrepreneurial action. For instance, why do some individuals undertake entrepreneurial action to destroy value, take advantage of the susceptible, and/or damage nature? Why does entrepreneurial action sometimes lead to physical, psychological, and/or emotional suffering? Is there a motivation that is the antithesis to prosocial motivation? That is, how do we examine the motivations of individuals who want to take entrepreneurial action to hurt or weaken other people or the natural environment (if such individuals exist)? These thought experiments may be useful in finding a terrain through which to begin to try to blaze a new trail.

New research questions, theories, and topics are also likely to broaden the range of research methods and vice versa. In the past, entrepreneurial scholars have broadened the range of research methods by taking methodological developments from other fields and applying them in the entrepreneurial context. However, similar to borrowing theories for application in the field of entrepreneurship, employing methods from other fields will likely necessitate some re-working, which may in itself contribute back to the initial source. Researchers also have the chance to engage in bricolage by considering the methods currently available and combining them in new ways to reveal novel grounds for theorizing and empirical testing. For example, we (along with Robert Baron) attempted bricolage by combining three basic methodological approaches - a conjoint study, an experimental manipulation, and an "intercepts-only" model-to help us better understand an issue that would have been challenging to test otherwise (see Shepherd et al., 2013). 


\section{IMPLICATIONS FOR ENTREPRENEURIAL JOURNALS}

Crowding out also happens during the journal review process when editors and reviewers take a more conservative approach because they are more concerned with errors of commission (i.e., publishing a paper that lessens the journal's legitimacy) than with errors of omission (i.e., turning down a paper that is riskier but could be very impactful). As a result, editors and reviewers often decide to "play it safe," deciding to accept only papers that fit their particular mold and are "done well" regardless of misgivings about the size of the work's contribution. While this conservative approach may work out in the short term, it is likely to lead to a stagnant field with inflexible borders, narrow questions, and tricky turf battles. If this occurs in entrepreneurship, we, as entrepreneurship scholars, will become the exact opposite of what we study.

So where is the field headed? Well, that depends on changes in the phenomena (which are difficult to predict) and where we, as a community of scholars, blaze new trails through publishing high-quality research papers. In this book, we focus on the latter-where we, as a community of scholars, can take the field through trailblazing-because scholarly knowledge is within our control. In this book, we present some trailblazing possibilities, possibilities that we believe hold great promise for future research to make important contributions to the continued development of the field. These possibilities are by no means an exhaustive list. Indeed, even within a particular topic of interest, there is almost an infinite array of research questions possible. It is our sincere hope that this book stimulates new exploratory research whether or not it is along the lines outlined herein.

In Fig. 1.1, we illustrate the framework for the book. In the next chapter (Chap. 2), we lay out the basis for trailblazing in terms of the generation, refinement, and exploitation of potential opportunities and the benefits generated for the entrepreneur (and/or the entrepreneurial firm) and/or others. In Chap. 3, we extend the notion of the "potential" opportunity to recognize that failure is a frequent outcome of entrepreneurial action that can also benefit the entrepreneur (and/or the entrepreneurial firm) and/or others primarily through learning from the experience. In Chap. 4, we describe how trailblazing can involve combining the operational processes of innovation and the various aspects of the entrepreneurial process to provide a deeper explanation of entrepreneurial activities and outcomes (including failure). The entrepreneurial process is (or microentrepreneurial processes are) embedded in a number of environments that 


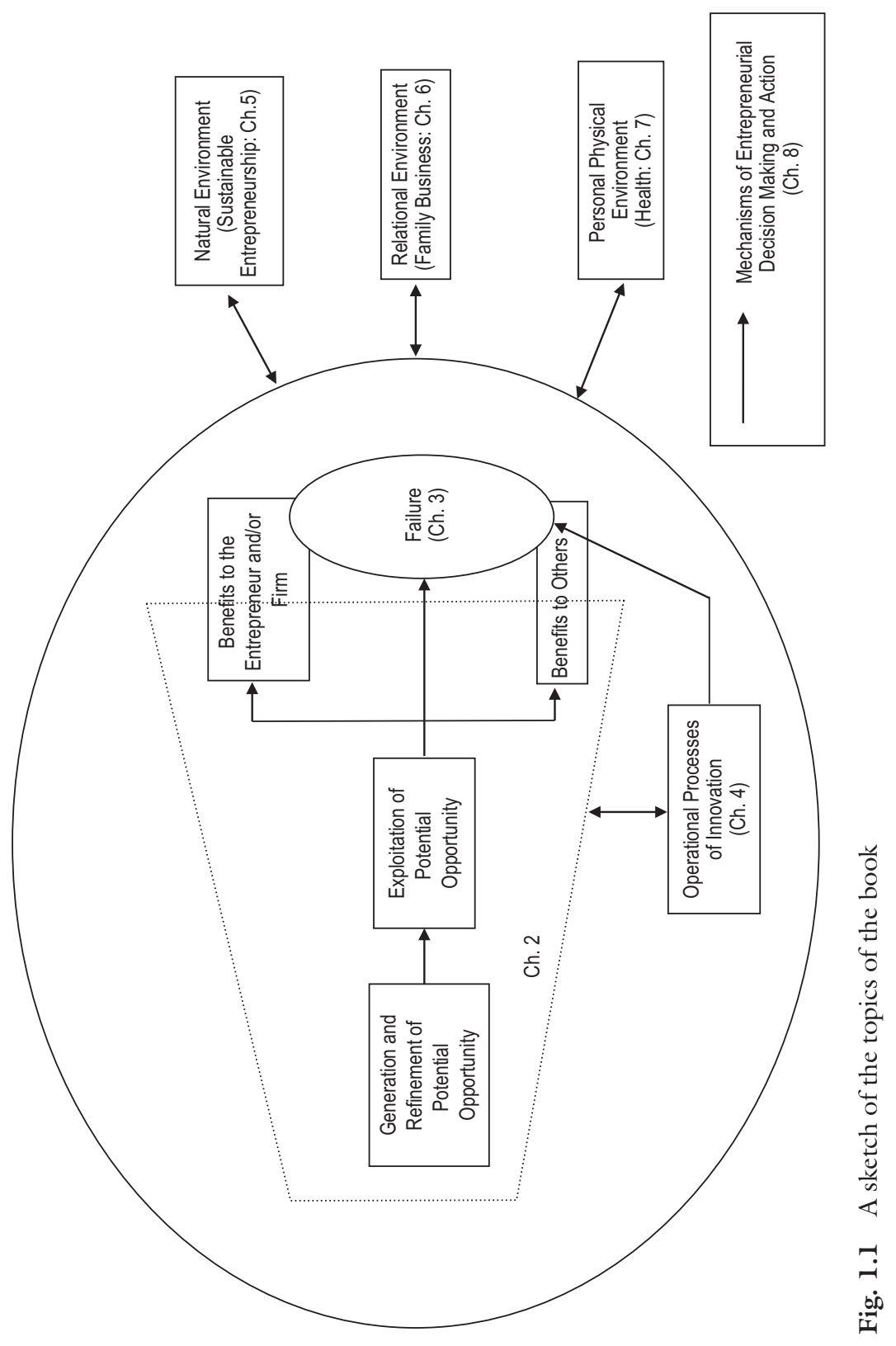


can trigger new paths of knowledge creation. Specifically, by exploring the entrepreneurial process in the natural environment, we can advance our understanding of sustainable entrepreneurship (Chap. 5); in the relational environment, we can advance our understanding of the family's role in entrepreneurial businesses (Chap. 6); and in the personal physical environment, we can gain a deeper understanding of how health impacts entrepreneurial action and how entrepreneurial action impacts health (of the entrepreneur and/or others) (Chap. 7). Although each chapter details the possible mechanisms underlying the proposed relationships (e.g., emotion, cognition, and motivation), we recognize that a central core assumption is that entrepreneurial actions are largely driven by decision making. In Chap. 8, we make explicit the role of decision making by explaining how entrepreneurial decision-making research can help blaze new trails in the field of entrepreneurship. Next, we describe each chapter in more detail.

In Chap. 2, we build on previous work (e.g., Shepherd, 2015) to investigate the central aspect of entrepreneurship — the opportunity — and build a deeper understanding of the possibilities of research from exploring (1) how the entrepreneurial process involves the mutual adjustment of the entrepreneur, a community of practice, and the nature of the potential opportunity over time; (2) how entrepreneurial activities inform and motivate opportunity beliefs as a micro-foundation of entrepreneurial action; (3) how entrepreneurial cognitions influence emotions and vice versa as a basis for a more dynamic and "hot" perspective of entrepreneurial thinking; and (4) how idiosyncratic motivations and knowledge can lead to entrepreneurial action that "does good" for others.

In Chap. 3, we build on our previous work (e.g., Shepherd, 2003; Shepherd, Patzelt, Williams, \& Warnecke, 2014; Shepherd, Patzelt, \& Wolfe, 2011) to acknowledge the frequency of failure given the uncertainty of the entrepreneurial process-failure of projects within an established firm and the failure of entrepreneurial firms. We then highlight how future research can make an important contribution to knowledge and open up new ground for subsequent research by exploring (1) the financial, social, and psychological consequences of failure; (2) the inter-relationships between the financial, social, and/ or psychological outcomes of experiencing failure, including magnifying and dampening effects; and (3) the processes of sensemaking and learning from failure, especially those related to developing plausible stories of failure. 
In Chap. 4, we highlight the importance of managing the entrepreneurial process and discuss how building on the innovation and operations management literatures provides a strong foundation from which numerous explorations can take place. In particular, although knowledge is central to the generation and refinement of a potential opportunity, we do not have a good understanding of how to manage that knowledge and, for that matter, what motivations lead to entrepreneurial actions. In this chapter, we describe the stepping stones of absorptive capacity, stage gates, and operations management more generally and start to lay them out in unsettled terrain in the field of entrepreneurship to provide an indication of the vitality generated by future trailblazing work in this area. Such trailblazing not only creates vitality to the field of entrepreneurship but also has the potential to revitalize these topics in the fields of innovation and operations management.

In Chap. 5, we build on our previous work (e.g., Patzelt \& Shepherd, 2011; Shepherd \& Patzelt, 2011) to offer sustainable entrepreneurship as the link between what is to be sustained (i.e., nature, life support, and community) and what is to be developed (broadly construed to include economic and non-economic gains to individuals, the economy, and society) through entrepreneurial actions. We explore the possibilities of research questions related to what is to be sustained and what is to be developed in sustainable entrepreneurship. We also explore entrepreneurs as a link between the scientific community and the end-user community. This is important because scientists' research-based knowledge has the potential to influence the sustainability of end users' development behaviors, but there are numerous obstacles to this occurring. Entrepreneurial action is a mechanism for overcoming some of these obstacles and thereby linking the scientific and user communities for sustainable development outcomes.

In Chap. 6, we build on our previous work (e.g., Shepherd, 2016) to begin to establish a stronger link between entrepreneurship and family business to build knowledge in both fields. Specifically, we explore (1) how a potential opportunity for a family business changes as a result of the interactions between sub-communities of inquiry inside and outside the family, the business, and the family business as well as how these subcommunities can be transformed by the entrepreneurial process; (2) how the entrepreneurial process and the notion of socio-emotional wealth intertwine to provide the possibilities for new insights into the entrepreneurial action and performance of family businesses; and (3) how family 
businesses have the capability and motivation for compassion organizing to alleviate the suffering of people inside and outside the family and inside and outside the business.

In Chap. 7, we build on our previous work (Shepherd \& Patzelt, 2015) to highlight the need for research linking entrepreneurial action to health outcomes and health to entrepreneurial outcomes. Such future research could have a substantial impact on the health of individuals. This approach suggests a number of terrains for which trailblazing could be highly beneficial. We believe that future entrepreneurship research should explore how health influences the decision to pursue an entrepreneurial career-the creation of a new organization and/or the pursuit of a potential opportunity. However, there is also likely a reciprocal relationship. We identify a number of research opportunities to explore how an entrepreneurial career can influence health through stress, emotional reactions, and socioeconomic status. In addition, as a consistent theme throughout the book, we believe that by considering entrepreneurial action as a tool that can be used for good, researchers need to investigate the path between entrepreneurial action and the health of others.

In Chap. 8, we build on our previous work (e.g., Shepherd, 2011; Shepherd, Williams, \& Patzelt, 2015) to point out that entrepreneurial decision making represents an extreme decision-making context faced by many corporate and independent entrepreneurs, a context high in uncertainty, time pressure, emotions, and consequential extremes. We explore research possibilities on the topics of opportunity-assessment decisions, entrepreneurial career decisions, decisions on funding entrepreneurial action, and biases and heuristics in entrepreneurial decision making. We also acknowledge a foundation of multi-level research on decision making in the entrepreneurial context and explore future research opportunities to build upon it. This exploration is organized conceptually as a hierarchy of levels below and above the level of the individual, and we use conjoint analysis as a methodological framework to keep these ideas anchored in what is empirically possible.

\section{Conclusion}

Through this book, we present a challenge (to ourselves and anyone else who will listen) for future research to build a stronger, more complete understanding of entrepreneurial phenomena. To achieve this strength and completeness, researchers (and journals) must accept that 
there is not one correct approach or answer in this field, and they must welcome numerous viewpoints, including those from different paradigms and multi-paradigms. Indeed, scholars have begun to recognize a "post-paradigm war" approach to building fields of knowledge (Romani, Primecz, \& Topçu, 2011) - a multi-paradigm perspective (e.g., Gioia \& Pitre, 1990) - that emphasizes a more complete picture of the phenomena at hand. This more complete picture of entrepreneurial phenomena will likely come from scholars who undertake at least some trailblazing projects; from scholars who broaden the range of research questions, the potential outcomes of entrepreneurial action, and the selection and combination of research methods; and from researchers who avoid the endless debates about the margins of the field and its sub-fields or about whether one theoretical or philosophical lens is superior to another.

\section{Note}

1. We acknowledge that some scholars may argue that we are lacking enough incremental research (e.g., there are calls for more replication studies). However, thinking about the future of the field of entrepreneurship, we are far more worried about "exploitation" overtaking "exploration" (consistent with March, 1991) than vice versa.

\section{REFERENCES}

Burrell, G., \& Morgan, G. (1979). Sociological paradigms and organisational analysis (Vol. 248). London: Heinemann.

Busenitz, L. W., West, G. P., Shepherd, D., Nelson, T., Chandler, G. N., \& Zacharakis, A. (2003). Entrepreneurship research in emergence: Past trends and future directions. Journal of Management, 29, 285-308.

Carlsson, B., Braunerhjelm, P., McKelvey, M., Olofsson, C., Persson, L., \& Ylinenpää, H. (2013). The evolving domain of entrepreneurship research. Small Business Economics, 41, 913-930.

Cole, S. (1983). The hierarchy of the sciences? American Journal of Sociology, $89(1), 111-139$.

Davidsson, P. (2003). The domain of entrepreneurship research: Some suggestions. Advances in Entrepreneurship, Firm Emergence and Growth, 6(3), 315-372.

Fiet, J. O. (2007). A prescriptive analysis of search and discovery. Journal of Management Studies, 44(4), 592-611. 
Gartner, W. B. (1990). What are we talking about when we talk about entrepreneurship? Journal of Business Venturing, 5(1), 15-28.

Gioia, D. A., \& Pitre, E. (1990). Multiparadigm perspectives on theory building. Academy of Management Review, 15(4), 584-602.

Glynn, M. A., Barr, P. S., \& Dacin, M. T. (2000). Pluralism and the problem of variety. Academy of Management Review, 25(4), 726-734.

Kuhn, T. S. (2012). The structure of scientific revolutions. Chicago, IL: University of Chicago Press.

Levitt, B., \& March, J. G. (1988). Organizational learning. Annual Review of Sociology, 14, 319-340.

Lewis, M. W., \& Grimes, A. I. (1999). Metatriangulation: Building theory from multiple paradigms. Academy of Management Review, 24(4), 672-690.

McGrath, R. G. (1999). Falling forward: Real options reasoning and entrepreneurial failure. Academy of Management Review, 24(1), 13-30.

Patzelt, H., \& Shepherd, D. A. (2011). Recognizing opportunities for sustainable development. Entrepreneurship Theory and Practice, 35(4), 631-652.

Pfeffer, J. (1993). Barriers to the advance of organizational science: Paradigm development as a dependent variable. Academy of Management Review, 18(4), 599-620.

Romani, L., Primecz, H., \& Topçu, K. (2011). Paradigm interplay for theory development: A methodological example with the Kulturstandard method. Organizational Research Methods, 14(3), 432-455.

Shane, S., \& Venkataraman, S. (2000). The promise of entrepreneurship as a field of research. Academy of Management Review, 25(1), 217-226.

Shepherd, D. A. (2003). Learning from business failure: Propositions of grief recovery for the self-employed. Academy of Management Review, 28(2), 318-328.

Shepherd, D. A. (2011). Multilevel entrepreneurship research: Opportunities for studying entrepreneurial decision making. Journal of Management, 37(2), 412-420.

Shepherd, D. A. (2015). Party on! A call for entrepreneurship research that is more interactive, activity based, cognitively hot, compassionate, and prosocial. Journal of Business Venturing, 30(4), 489-507.

Shepherd, D. A. (2016). An emotions perspective for advancing the fields of family business and entrepreneurship: Stocks, flows, reactions, and responses. Family Business Review, 1-8.

Shepherd, D. A., \& Patzelt, H. (2011). The new field of sustainable entrepreneurship: Studying entrepreneurial action linking "what is to be sustained" with "what is to be developed". Entrepreneurship Theory and Practice, 35(1), $137-163$.

Shepherd, D. A., Patzelt, H., \& Baron, R. A. (2013). "I care about nature, but ...": Disengaging values in assessing opportunities that cause harm. Academy of Management Journal, 56(5), 1251-1273. 
Shepherd, D. A., \& Patzelt, H. (2015). The "heart" of entrepreneurship: The impact of entrepreneurial action on health and health on entrepreneurial action. Journal of Business Venturing Insights, 4, 22-29.

Shepherd, D. A., Patzelt, H., Williams, T. A., \& Warnecke, D. (2014). How does project termination impact project team members? Rapid termination, 'creeping death', and learning from failure. Journal of Management Studies, 51(4), 513-546.

Shepherd, D. A., Patzelt, H., \& Wolfe, M. (2011). Moving forward from project failure: Negative emotions, affective commitment, and learning from the experience. Academy of Management Journal, 54(6), 1229-1259.

Shepherd, D. A., Williams, T. A., \& Patzelt, H. (2015). Thinking about entrepreneurial decision making: Review and research agenda. Journal of Management, $41(1), 11-46$.

Venkataraman, S. (1997). The distinctive domain of entrepreneurship research. In J. Katz (Ed.), Advances in entrepreneurship, firm emergence, and growth (pp. 119-138). Greenwich: JAI Press.

Wiklund, J., Davidsson, P., Audretsch, D. B., \& Karlsson, C. (2011). The future of entrepreneurship research. Entrepreneurship Theory and Practice, 35(1), 1-9.

Open Access This chapter is distributed under the terms of the Creative Commons Attribution 4.0 International License (http://creativecommons.org/licenses/by/4.0/), which permits use, duplication, adaptation, distribution and reproduction in any medium or format, as long as you give appropriate credit to the original author(s) and the source, provide a link to the Creative Commons license and indicate if changes were made.

The images or other third party material in this chapter are included in the work's Creative Commons license, unless indicated otherwise in the credit line; if such material is not included in the work's Creative Commons license and the respective action is not permitted by statutory regulation, users will need to obtain permission from the license holder to duplicate, adapt or reproduce the material.

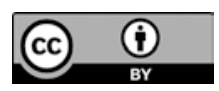

